\title{
CO liberated from CORM-2 modulates the inflammatory response in the liver of thermally injured mice
}

\author{
Bing-Wei Sun, Yan Sun, Zhi-Wei Sun, Xi Chen
}

\author{
Bing-Wei Sun, Yan Sun, Zhi-Wei Sun, Xi Chen, Department of \\ Burns and Plastic Surgery, Affiliated Hospital, Jiangsu University, \\ Zhenjiang 212001, Jiangsu Province, China \\ Supported by National Natural Science Foundation of China, \\ No. 30772256 \\ Correspondence to: Dr. Bing-Wei Sun, Department of Burns \\ and Plastic Surgery, Affiliated Hospital, Jiangsu University, 438 \\ Jiefang Rd. Zhenjiang 212001, Jiangsu Province, \\ China.sunbinwe@hotmail.com \\ Telephone: +86-511-85026183 Fax: +86-511-85029089 \\ Received: July 12, $2007 \quad$ Revised: September 28, 2007
}

\begin{abstract}
AIM: To explore the effects of CO-releasing molecules [tricarbonyldichlororuthenium ( II ) dimer, CORM-2]liberated $\mathrm{CO}$ on attenuation of inflammatory responses in liver of an experimental animal model of thermal injury and to investigate the associated potential mechanisms.

METHODS: Thirty-six mice were assigned to three groups in three respective experiments. In each experiment, mice in sham group $(n=4)$ received sham thermal injury, whereas mice in burn group $(n=4)$ received a $15 \%$ of total body surface area (TBSA) fullthickness thermal injury, and mice in burn + CORM-2 group $(n=4)$ received the same thermal injury with immediate administration of CORM-2 $(8 \mathrm{mg} / \mathrm{kg}$, iv). Hepatic tissue sections were stained with hematoxylin and eosin and examined under a light microscope. Levels of aminotransferases (ALT and AST) and nitric oxide (NO) were measured by biochemical methods. Tumor necrosis factor- $\alpha$ (TNF- $\alpha$ ) and interleukin (IL-1 $\beta$ ) activity, and the protein expression of iNOS and $\mathrm{HO}-1$ in serum and tissue homogenates were assessed. In in vitro experiments, Kupffer cells were stimulated with LPS $(10 \mu \mathrm{g} / \mathrm{mL})$ for $4 \mathrm{~h}$ in the presence or absence of CORM-2 (10-100 $\mu \mathrm{mol} / \mathrm{L})$. Subsequently, the expression levels of TNF- $\alpha$ and NO production were assessed.
\end{abstract}

RESULTS: Pro-inflammatory mediators (TNF- $\alpha$, IL$1 \beta, N O$ ) in serum and liver homogenates of thermally injured mice were significantly reduced by CORM-2 administration. This was accompanied by a decrease in the expression of iNOS while an increase in the expression of $\mathrm{HO}-1$ in the liver tissue. In parallel, the concentrations of TNF- $\alpha$ and NO in supernatants of LPS-stimulated Kupffer cells co-incubated with CORM-2 $(10-100 \mu \mathrm{mol} / \mathrm{L})$ were also markedly decreased.
Histological examination demonstrated that CORM-2 could attenuate the leukocytes infiltration to the liver tissue.

CONCLUSION: CORM-released CO modulates liver inflammation and significantly protects liver injury in burn mice by inhibiting the expression of iNOS and NO production, down-regulating the expression of proinflammatory mediators (TNF- $\alpha$, IL-1 $\beta$ ).

\section{(c) 2008 WJG. All rights reserved.}

Key words: Carbon monoxide; Thermal injury; Liver; Inflammation

Peer reviewers: Eddie Wisse, Professor, Irisweg 16, Keerbergen 3140, Belgium; Alastair D Burt, Professor, Dean of Clinical Medicine, Faculty of Medical Sciences, Newcastle University, Room 13, Peacock Hall, Royal Victoria Infirmary, Newcastle upon Tyne NE1 4LP, United Kingdom

Sun BW, Sun Y, Sun ZW, Chen X. CO liberated from CORM-2 modulates the inflammatory response in the liver of thermally injured mice. World J Gastroenterol 2008; 14(4): 547-553 Available from: URL: http://www.wjgnet.com/1007-9327/14/547. asp DOI: http://dx.doi.org/10.3748/wjg.14.547

\section{INTRODUCTION}

It is well known that endogenous carbon monoxide (CO), a bi-product of inducible heme oxygenase (HO-1), can modulates inflammation. In addition, some experiments have determined that the administration of exogenous $\mathrm{CO}$ inhibits lipopolysaccharide (LPS)-induced production of cytokines both in vivo and in vitro, and consequently exhibits important cytoprotective function and anti-inflammatory properties that are beneficial for the resolution of acute inflammation ${ }^{[1-3]}$.

Recently, transitional metal carbonyls have been identified as potential CO-releasing molecules (CO$\mathrm{RMs}$ ) with the potential to facilitate the pharmaceutical use of $\mathrm{CO}$ by delivering it to tissues and organs ${ }^{[4]}$. CORMs have been shown to act pharmacologically in rat aortic and cardiac tissue where liberation of $\mathrm{CO}$ produced vasorelaxant effects ${ }^{[5-8]}$ and decreased myocardial ischemiareperfusion damage ${ }^{[0,10]}$, respectively.

Our recent study has confirmed that tricarbonyldichlor oruthenium (II) dimer (CORM-2), one of the novel group 
of CORMs, inhibited the leukocytes sequestration in liver ${ }^{[11]}$ and down-regulated inflammatory response in the lung $^{[12]}$ of burn-challenged mice. However, the regulating mechanisms of CORM-2 in the inflammatory response in the liver of burn-challenged mice remain unknown. Severe burn injury is a complicated process that involves several host responses, including inflammation, immune response and even systemic inflammatory response syndrome (SIRS). Different cytokines are likely to be produced during these host responses. Some of these cytokines may be produced in response to the thermal injury. Also, the pathophysiological changes seen in SIRS are often not due to the infectious organism itself but instead to the uncontrolled production of pro-inflammatory cytokines and chemokines, including tumor necrosis factor (TNF)- $\alpha$, interleukin (IL)-1b. Accumulation of these mediators leads to leukocyte recruitment, capillary leak and tissue damage, ultimately producing the lethality of sepsis ${ }^{[13-15]}$.

Based on these preliminary observations, in this study, we employed CORM-2 to determine whether it can exert the potential influence to modulate the important inflammatory mediators ( $\mathrm{TNF}-\alpha, \mathrm{IL}-1 \beta$ and $\mathrm{NO}$ ) in the liver of thermally injured mice.

\section{MATERIALS AND METHODS}

\section{Materials}

Tricarbonyldichlororuthenium (II) dimer (CORM-2) was obtained from Sigma Aldrich and solubilized in dimethyl sulfoxide (DMSO) to obtain a $10 \mathrm{mmol} / \mathrm{L}$ stock. Polyclonal or monoclonal antibodies against HO-1 and iNOS were purchased from Santa Cruz Biotechnology Inc. All other chemicals were of analytical reagent grade and obtained from Sigma-Aldrich (Shanghai Trading Co. Ltd.) unless otherwise stated.

\section{Animal and burn protocol}

Thirty-six male C57BL/ 6 mice, weighing $20 \pm 2$ g, were fed a standard laboratory diet and water ad libitum. Mice were assigned to three groups in three respective experiments. In each experiment, mice in sham group $(n=4)$ received sham thermal injury, whereas mice in burn group $(n=4)$ received a $15 \%$ of total body surface area (TBSA) full-thickness thermal injury and CORM-2 group $(n=4)$ received the same thermal injury with immediate administration of CORM-2 (8 mg/kg, iv). The experimental protocol was approved by the Council on Animal Care at Jiangsu University on the protection and the welfare of animals. Under anesthesia with spontaneous inhalation of isoflurane$\mathrm{N}_{2} \mathrm{O}$ (Abbott Laboratories, Missisauga, ON, Canada) in a $60 \%$ oxygen $-40 \%$ nitrogen mixture, the dorsum of each mouse was shaved and the mice were subjected to a $15 \%$ of total body surface area (TBSA) full-thickness thermal injury as previously described ${ }^{[16,17]}$. Sham animals were immersed in a room temperature water bath. All animals were resuscitated with $1.5 \mathrm{~mL}$ saline immediately after thermal (or sham) injury. No wound care was required for the burn wounds. This burn method achieves a histologically proven, full-thickness scald injury ${ }^{[18,19]}$. The animals were sacrificed at $24 \mathrm{~h}$ after experimental manipulation.

\section{Histologic studies}

The liver specimens harvested from different groups of mice were immersed in $40 \mathrm{~mL} / \mathrm{L}$ formaldehyde solution after $24 \mathrm{~h}$ of the thermal injury. The tissues were embedded in paraffin wax, serially sectioned, and stained with hematoxylin-eosin. Liver morphologic characteristics were evaluated under light microscope.

\section{Isolation and culture of Kupffer cells}

In in vitro experiment, the effect of CORM-2 on Kupffer cells was studied by isolating Kupffer cells from the normal livers. Liver perfusion was performed using a modification of the two-step collagenase perfusion technique introduced by previous studies ${ }^{[20,21]}$. Briefly, the liver was perfused through the portal vein with D-Hank's solution until became blood-free, and then with Hank's solution containing $0.5 \mathrm{~g} / \mathrm{L}$ collagenase $\mathrm{IV}$. The latter was administered by recirculation until the vessels were digested (up to $20 \mathrm{~min}$ ). The liver was then scraped using a cell scraper, filtered through a $100-\mu \mathrm{m}$ filter, and stirred in Hank's solution containing $2.5 \mathrm{~g} / \mathrm{L}$ pronase and $0.05 \mathrm{~g} / \mathrm{L}$ Dnase at $37^{\circ} \mathrm{C}$ for $20 \mathrm{~min}$. After three times of centrifugation and washing at $300 \mathrm{r} / \mathrm{min}$ for $10 \mathrm{~min}$ at $4^{\circ} \mathrm{C}$ in Gey's balanced salt solution (GBSS), cells were centrifuged in an $180 \mathrm{~g} / \mathrm{L}$ Nycodenz gradient at $2500 \mathrm{r} / \mathrm{min}$ for $20 \mathrm{~min}$. Kupffer cells were carefully sucked by cusp-straws at the pearl layer inderphase. Purified Kupffer cell fractions were then obtained by centrifugal elutriation. The viability of Kupffer cells prepared was more than $95 \%$ as determined by trypan blue exclusion. The purity of Kupffer cells was greater than $90 \%$ based on a peroxidase activity assay ${ }^{[22]}$.

Kupffer cells were cultured in RPMI 1640 medium containing antibiotics (penicillin $100 \mathrm{U} / \mathrm{mL}$; streptomycin $100 \mathrm{mg} / \mathrm{mL}$ ), $2 \mathrm{mmol} / \mathrm{L}$ glutamine, and $100 \mathrm{~mL} / \mathrm{L}$ fetal calf serum. The cells at a density of $1 \times 10^{6} / \mathrm{mL}$ were cultured in 24-well culture plates and co-incubated with LPS $(10 \mu \mathrm{g} / \mathrm{mL})$ and different concentrations of CORM-2 $(10,50,100 \mu \mathrm{mol} / \mathrm{L})$ for $4 \mathrm{~h}$. The supernatants were collected and TNF- $\alpha$ and NO concentrations were measured using the methods described below.

\section{Measurement of serum level of transaminases, TNF- $\alpha$ and IL-1 $\beta$ levels in serum, tissue homogenate and cell culture supernatants}

Blood samples were obtained by cardiac puncture of the left ventricle. The samples were stored in serum tubes (Capiject, Terumo Medical Corporation, USA) and immediately centrifuged at $6500 \mathrm{r} / \mathrm{min}$ for $5 \mathrm{~min}$. Evaluation of hepatocellular injury was performed by determining the enzymatic activity of the alanine aminotransferase (ALT) and aspartate aminotransferase (AST) in serum samples using a commercial kit (Boehringer Manheim, Munich, Germany) according to the manufacturer's instructions. Concentrations of TNF- $\alpha$ and IL-1 $\beta$ levels in serum, tissue homogenate and supernatants of cell culture were assayed by enzyme-linked immunosorbent assay kits (Genzyme, Corp., Cambridge, MA) following the manufacturer's instructions. 

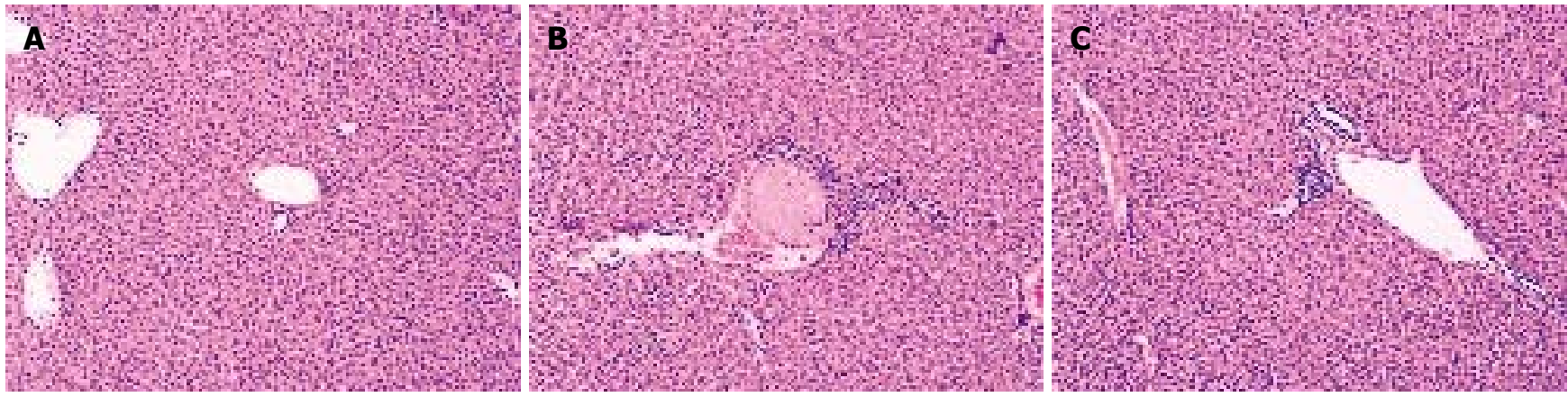

Figure 1 Histologic results of liver tissue after staining with hematoxylin and eosin (HE, $\times 100)$. Mice were challenged with thermal injury and immediately intravenously injected with CORM-2 (8 mg/kg). A: Sham group; B: Burn group; C: Burn + CORM-2 group.

\section{Measurement of NO in serum, tissue homogenate and cell culture supernatants}

Nitric oxide (NO) was measured by a microplate assay using Griess reagent, which produces a chromophore with the nitrite ${ }^{[23]}$. Briefly, $100 \mu \mathrm{L}$ of supernatant was removed and incubated with $100 \mu \mathrm{L}$ of Griess reagent $(10 \mathrm{~g} / \mathrm{L}$ sulfanilamide and $1 \mu \mathrm{g} / \mathrm{L} \mathrm{N}$-1-naphthylethylenediamine dihydrochloride in $25 \mathrm{~mL} / \mathrm{L}$ phosphoric acid) in a 96-well plate. The plate was incubated for $10 \mathrm{~min}$ at room temperature. Nitrite production was quantified spectrophotometrically using an automated colorimetric procedure. Absorbance at $540 \mathrm{~nm}\left(A_{540}\right)$ was measured using a microplate reader (Bio-Tek, USA). The nitrite concentration was calculated by comparing samples with standard solutions of sodium nitrite produced in the culture medium. All samples were assayed in triplicate. Results were expressed as $\mu \mathrm{mol} / \mathrm{L}$.

\section{Western blot analysis}

Tissues were homogenized for extract preparations in icecold mild lysis buffer containing $10 \mathrm{~mL} / \mathrm{L}$ Nonidet P-40, $0.15 \mathrm{~mol} / \mathrm{L} \mathrm{NaCl}, 0.01 \mathrm{~mol} / \mathrm{L}$ sodium phosphate ( $\mathrm{pH} 7.2$ ), $2 \mathrm{mmol} / \mathrm{L}$ EDTA, $50 \mathrm{mmol} / \mathrm{L}$ sodium fluoride, 0.2 $\mathrm{mmol} / \mathrm{L}$ sodium vanadate, and $1 \mu \mathrm{g} / \mathrm{mL}$ aprotinin. The tissue homogenates were centrifuged at $20000 \times g$ for $15 \mathrm{~min}$ and supernatants were collected. SDS-PAGE was performed on equivalent amounts of protein samples using precast $7 \%$ resolving $/ 4 \%$ stacking Tris-HCl gels (Bio-Rad, Hercules, CA). Separated proteins were then transferred onto PVDF membranes (Amersham Pharmacia Biotech, Inc., Piscataway, NJ). Membranes were blocked in $50 \mathrm{~g} / \mathrm{L}$ nonfat milk in TBST (TBS buffer containing $1 \mathrm{~g} / \mathrm{L}$ Tween 20) for $1 \mathrm{~h}$ at room temperature. Blocked membranes were incubated in primary antibodies specific for mouse iNOS (1:2000 dilution) and HO-1 (1:5000 dilution) in TBST overnight at $4{ }^{\circ} \mathrm{C}$. Then the membranes were washed and probed with horseradish peroxidase-conjugated secondary antibody (Amersham Pharmacia Biotech, Inc.) for $1 \mathrm{~h}$ at room temperature. Chemiluminescence detection was performed with the Amersham enhanced chemiluminescence detection kit according to the manufacturer's instructions. To ensure a similar amount of protein in each sample, the membranes were "stripped off", reprobed with actin, developed with horseradish peroxidaseconjugated secondary antibody, and visualized by enhanced
Table 1 Liver injury estimated from serum ALT and AST levels

\begin{tabular}{llcc}
\hline Groups & $\boldsymbol{n}$ & AST (IU/L) & ALT (IU/L) \\
\hline Sham & 6 & $70.3 \pm 6.8$ & $38.5 \pm 6.1$ \\
Burn & 6 & $345.6 \pm 32.7^{\mathrm{b}}$ & $107.7 \pm 16.9^{\mathrm{b}}$ \\
Burn + CORM-2 & 6 & $189.9 \pm 24.3^{\mathrm{a}}$ & $58.6 \pm 9.7^{\mathrm{a}}$ \\
\hline
\end{tabular}

${ }^{\mathrm{b}} \mathrm{P}<0.01$ vs sham; ${ }^{\mathrm{a}} \mathrm{P}<0.05$ vs burn

chemiluminescence. The specific bands were quantified by densitometry (Bio-Rad GS-710 Densitometer).

\section{Statistical analysis}

Data were expressed as mean \pm SE. Statistical analysis was performed using ANOVA and Student's $t$-test for the comparisons. A $P$ value less than 0.05 was considered statistically significant.

\section{RESULTS}

\section{Histology}

Histological analysis showed that the liver sections from sham mice demonstrated a normal architecture, while thermal injury induced marked vacuolization and infiltration of the inflammatory cells to the tissue (Figure 1). After in vivo administration of CORM-2 (8 mg/ $\mathrm{kg}$, iv), granulocyte infiltrations were significantly decreased. However, CORM-2 did not improve the thermal injuryinduced congestion in liver sinusoids.

\section{Effect of CORM-2 on transaminases levels in burn-challenged mice serum}

Hepatocyte injury was evaluated by determining the serum concentrations of ALT and AST. At $24 \mathrm{~h}$ after a 15\% TBSA full-thickness thermal injury, serum hepatic transaminases (ALT and AST) were found to be markedly increased in the burn mice as compared to the sham mice $(P<0.05)$, whereas the corresponding values in the burn mice receiving CORM-2 $(8 \mathrm{mg} / \mathrm{kg}$, iv $)$ at the beginning of resuscitation were significantly decreased as compared to the burn mice without CORM-2 administration $(P<0.05$, Table 1$)$.

Effect of CORM-2 on TNF- $\alpha$ and IL-1 $\beta$ levels in serum and tissue homogenates of burn-challenged mice

At $24 \mathrm{~h}$ after a $15 \%$ TBSA full-thickness thermal injury, 

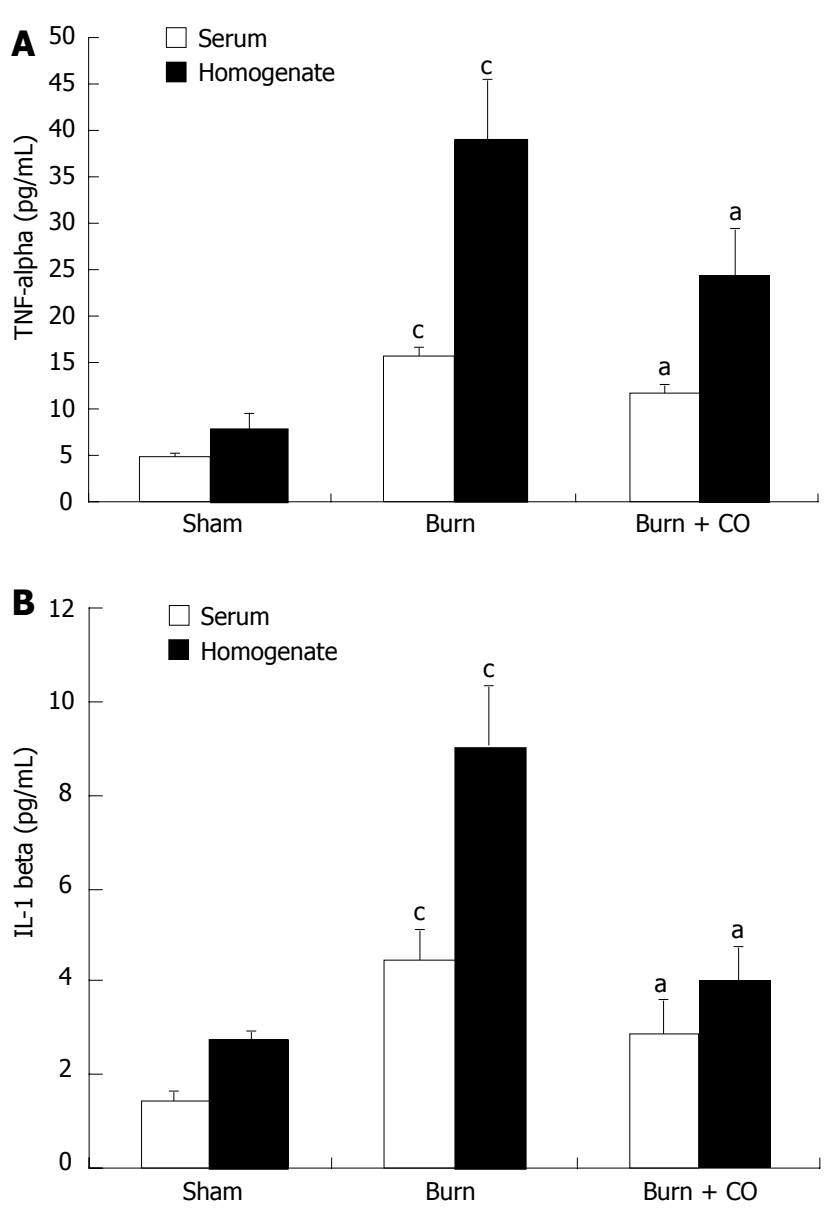

Figure 2 Effect of CORM-2 on TNF-a and IL-1 $\beta$ levels in serum and tissue homogenates of burn-challenged mice. Data are expressed as mean $\pm \mathrm{SE}$ of three experiments (three mice per group). ${ }^{a} P<0.05$ vs burn group; ${ }^{\mathrm{c}} P<0.05$ vs sham group.

TNF- $\alpha$ and IL-1 $\beta$ levels in serum and tissue homogenates of the burn-challenged mice were markedly increased compared to the sham mice. After administration of CORM-2, the elevation in serum and tissue homogenates levels of TNF- $\alpha$ and IL-1 $\beta$ was significantly abolished (Figure 2A and $\mathrm{B}$ ).

\section{Effect of CORM-2 on expression of iNOS and HO-1 in the liver of burn-challenged mice}

At $24 \mathrm{~h}$ after a 15\% TBSA full-thickness thermal injury, the expression of iNOS in liver tissue significantly increased compared to the sham mice. In vivo administration of CORM-2 $(8 \mathrm{mg} / \mathrm{kg}$, iv) resulted in a significant decrease in iNOS expression (Figure 3A and C). HO-1 expression in the liver of burn mice was markedly increased compared to sham mice. Interestingly, HO-1 expression in the liver of burn mice with administration of CORM-2 was more significantly increased as compared to the burn group (Figure $3 \mathrm{~A}$ and $\mathrm{B}$ ).

\section{Effect of CORM-2 on NO production in serum and tissue homogenates of burn-challenged mice}

As shown in Figure 4, production of $\mathrm{NO}$ was low in sham group. After burn challenge, $\mathrm{NO}$ levels in serum and tissue homogenates were significantly increased $(P<0.05$ vs
A
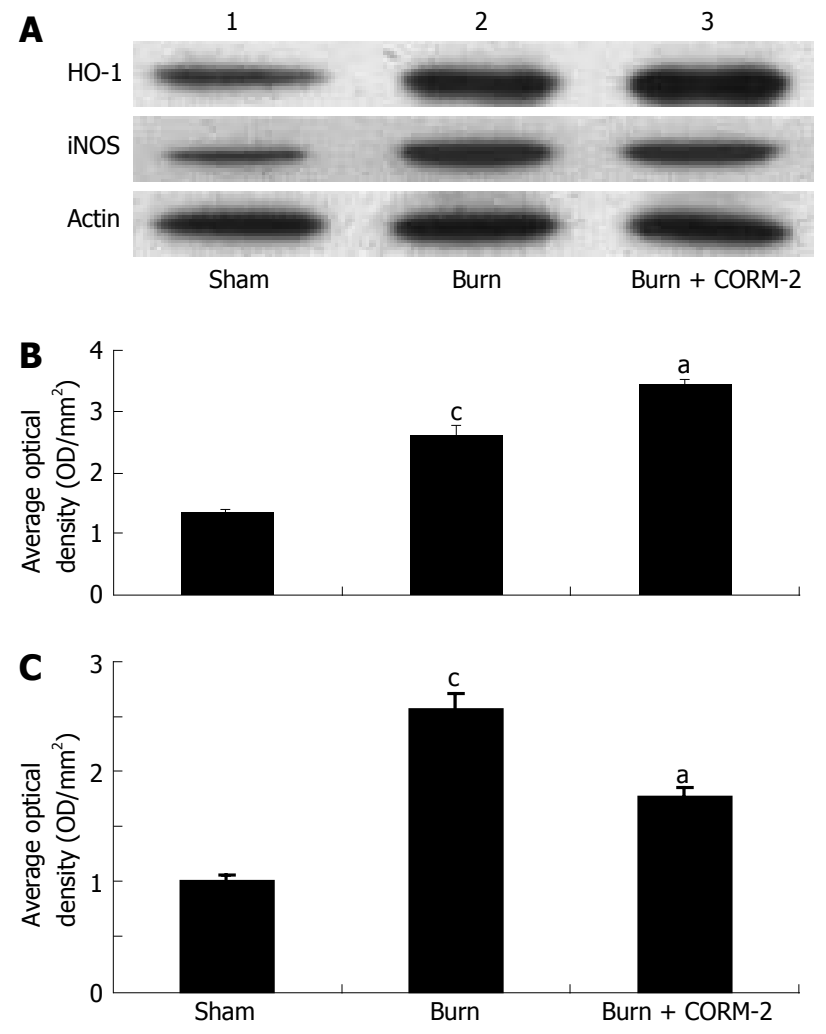

Figure 3 Effects of CORM-2 on protein expression of iNOS and HO-1 in the liver of burn-challenged mice. Protein expressions of iNOS and HO-1 were performed by Western blotting at $24 \mathrm{~h}$ after thermal injury. A: Representative experiment; B and C: Quantitative results (average absorbance, $A_{540}$ ) of three. ${ }^{a} P<0.05$ vs burn group; ${ }^{\circ} P<0.05$ vs sham group.

sham), whereas administration of CORM-2 significantly decreased the NO levels $(P<0.05 v$ s burn group).

\section{Effect of CORM-2 on NO and TNF- $\alpha$ levels in supernatants of Kupffer cells stimulated with LPS}

As shown in Figure 5, NO and TNF- $\alpha$ levels were low in controls. After Kupffer cells were stimulated by LPS $(10 \mu \mathrm{g} / \mathrm{mL})$ for $4 \mathrm{~h}, \mathrm{NO}$ and $\mathrm{TNF}-\alpha$ levels in supernatants were significantly increased as compared to controls $(P<0.05)$, while markedly decreased when Kupffer cells were co-incubated with LPS and CORM-2 $(P<0.05$ vs LPS group).

\section{DISCUSSION}

Recent studies have demonstrated various physiologic and immunologic alterations in acute inflammations associated with infection, trauma and thermal injury ${ }^{[24-27]}$. Increasing attention has been directed to the role of cytokines in the mechanisms of such alterations. TNF- $\alpha$, IL-1 $\beta$, IL-6, which are pro-inflammatory cytokines, are considered potential mediators of inflammation produced by immunoregulatory cells as well as by a variety of other cell types $^{[28]}$, and play a major role in the regulation of immune response and inflammation ${ }^{[29]}$.

It is well known that heme oxygenase-1 (HO-1), the inducible isoform of heme oxygenase which catalyzes the formation of the endogenous carbon monoxide (CO), 


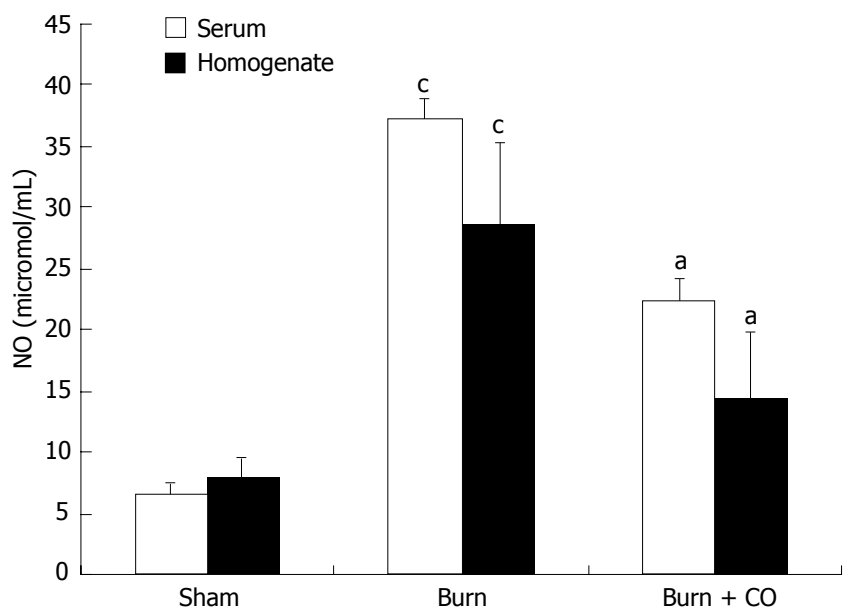

Figure 4 Effects of CORM-2 on NO level in serum and tissue homogenates of burn-challenged mice. Measurement of NO level was performed by a microplate assay using Griess reagent at $24 \mathrm{~h}$ after thermal injury. NO levels both in serum and tissue homogenates of thermally injured mice were markedly increased, but significantly inhibited by in vivo administration of CORM-2. ${ }^{a} P<0.05$ vs burn group; ${ }^{\mathrm{C}} P<0.05$ vs sham group.

biliverdin/bilirubin and ferrous iron, exhibits important anti-inflammatory properties that are beneficial for the resolution of acute inflammation ${ }^{[30]}$. Many experimental studies have highlighted the specific and independent role of exogenous $\mathrm{CO}$ (i.e. CO gas inhalation) in the modulation of inflammation ${ }^{[31]}$. Recently some new metal carbonyl-based compounds (CO-releasing molecules, CO-RMs) that have the ability to release CO in biological systems have been identified and synthesized. The vasoactive, antihypertensive and antirejection effects of CO-RMs have been demonstrated to be due to the CO liberated by the compounds. CORM-2, a DMSO-soluble CO-RM, also has exhibited anti-inflammatory actions in an in vitro model of LPS-stimulated murine macrophages. Thus, the aim of this study was to shed light on the role of CORM-2, as a exogenous CO, on the local and systemic inflammatory response induced by burn injury.

In this study, we found that HO-1 was significantly upregulated by thermal injury. Interestingly, HO-1 expression in the liver of thermal injury with administration of CORM-2 was more significantly increased compared to burn mice (Figure 3). This result indicated that not only major burn injury, a severe trauma, might significantly induce HO-1 expression, but also the increase of HO-1 expression can be further enhanced by the in vivo administration of CORM-2. Through the by-product (CO, and/or biliverdin), the potent cytoprotective and antiinflammatory functions were ultimately led to exert.

The data from this study showed that thermal trauma induced hepatocellular injury as evidenced by increased plasma ALT and AST levels. The in vivo administration of CORM-2 attenuated post-burn hepatocellular injury (Table 1). In parallel, after application of CORM-2, the elevation both in serum and tissue homogenates levels of TNF- $\alpha$ and IL-1 $\beta$ in burn-challenged mice was abolished (Figure 2). This result suggests that CORM-2 in the prevention of burn-induced liver damage may involve in down-regulation of the production of $\mathrm{TNF}-\alpha$, since
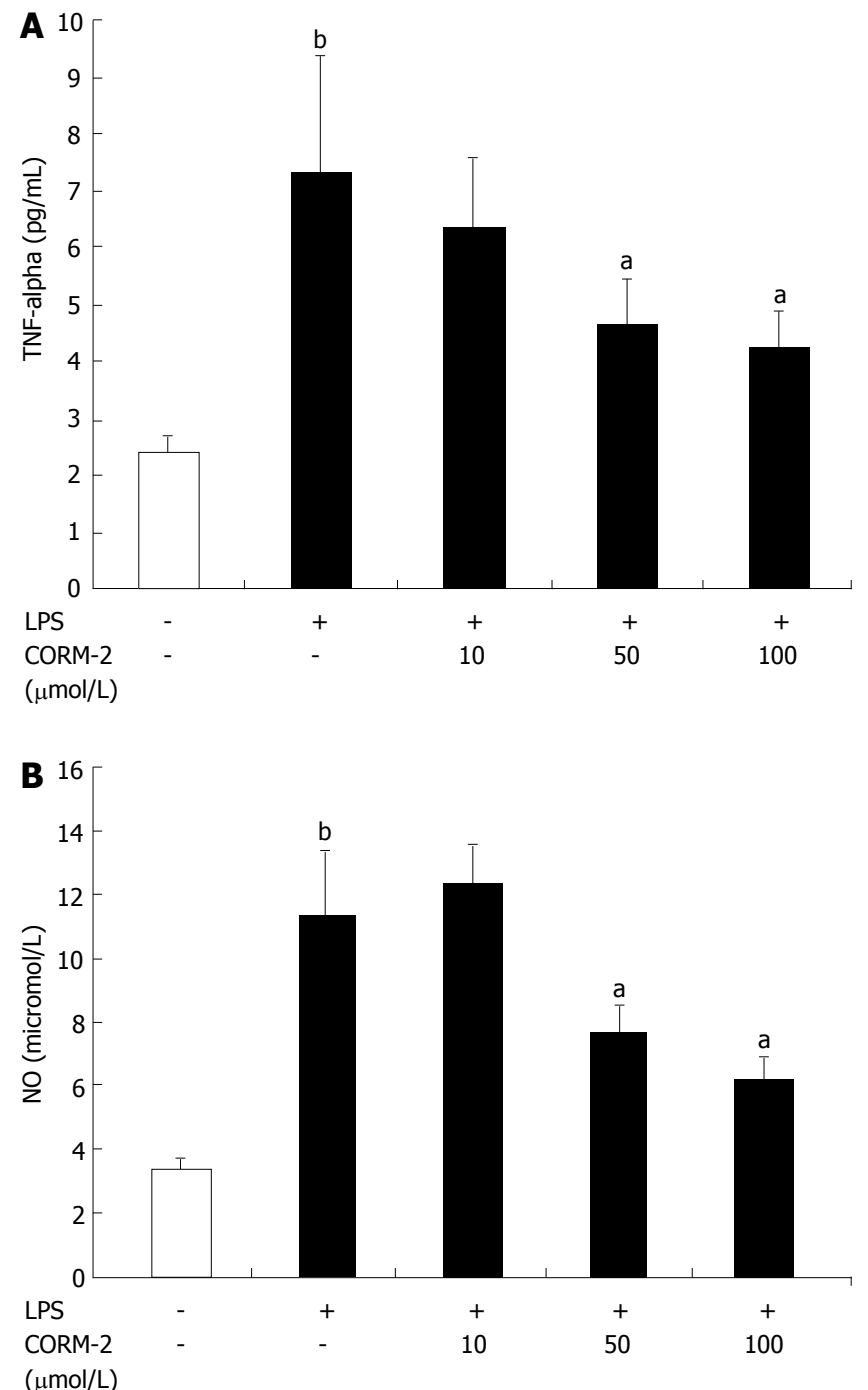

Figure 5 Effect of CORM-2 on levels of NO and TNF- $\alpha$ in supernatants of Kupffer cells stimulated with LPS. Kupffer cells were co-incubated with LPS and different concentrations of CORM-2 $(10-100 \mathrm{mmol} / \mathrm{L})$ for $4 \mathrm{~h}$. All values are expressed as means \pm SE $(n=3) .{ }^{b} P<0.01$ vs control; ${ }^{a} P<0.05$ vs LPS group.

TNF- $\alpha$ is an important mediator of hepatic inflammation in burn-induced liver damage. An alternative possibility is that the anti-inflammatory effects of CORM-2 are owing to its potential inhibition of the production and secretion of TNF- $\alpha$. These data indicated that CORM-2 exhibits, at least partly, an important cytoprotective function during the early period of thermal injury.

Based on current research findings, oxidative stress is believed to be the major causative agent to damage the organs distant from the original burn wound. Nitrosative stress initiates an inflammatory cascade that includes acute phase protein synthesis, up-regulation of inflammatory adhesion molecules, and pro-inflammatory cytokine release $^{[32,33]}$. Thus, tissue or organ injury after thermal trauma appears to be mediated both by reactive oxygen species (ROS) and reactive nitrogen species (RNS), such as hydroxyl radical, superoxide anion, hydrogen peroxide, and peroxynitrite. It has been demonstrated that burn injury is associated with lipid peroxidation mediated by ROS and is believed to be an important cause of oxidative damage to cellular membranes and, eventually, cell death ${ }^{[34]}$. Also, 
nitric oxide (NO) plays a crucial role in cellular injury in burns. It has been recognized that NO is produced by cNOS and/or iNOS in mice liver ${ }^{[35,36]}$. In this study, we found that thermal injury produced a significant upregulation in the inducible nitric oxide synthetase (iNOS) expression (Figure 3), thereby up-regulating iNOSmediated nitric oxide production. After administration of CORM-2, the iNOS protein expression was significantly decreased, it might effectively decrease the overabundance of NO, which produces significant cellular toxicity via several mechanisms ${ }^{[37]}$.

Lipopolysaccharide (LPS), a constituent of the Gramnegative bacterial cell wall, is the leading cause of sepsis, and when administered experimentally to macrophages or mice, mimics the same inflammatory responses. After LPS administration, there is a rapid increase in the proinflammatory mediators. The present study showed that the levels of TNF- $\alpha$ and NO in the supernatants of Kupffer cells stimulated by LPS were markedly increased compared to controls, while this increases was downregulated after the co-incubation with CORM-2 in a concentration-dependent manner (Figure 5). These results are in accordance with our in vivo experimental data, which indicated that CORM-2 effectively inhibited TNF- $\alpha$ expression and $\mathrm{NO}$ production both in serum and tissue homogenates of experimental models.

In summary, the present study clarifies the antiinflammatory and cytoprotective role of CORM-2, one of the novel CO-releasing molecules. Application of CORM-2 on thermally injured mice inhibited the expressions of TNF- $\alpha$ and IL- $1 \beta$ both in serum and tissue homogenates of experimental models. Also, iNOS protein expression in liver tissue was effectively inhibited in burn-challenged mice with treatment of CORM-2, this was accompanied by a decrease in NO level. In parallel, TNF- $\alpha$ and NO levels were decreased in LPS-stimulated Kupffer cells treated with CORM-2. Taken together, these findings indicate that CORM-released CO modulates liver inflammation in burn-challenged mice by interfering with TNF- $\alpha$, IL-1 $\beta$ and NO production, and iNOS and HO-1 protein expressions, thereby suppressing inflammatory response in the liver of experimental models. Further studies are required to understand the detail mechanisms of anti-inflammatory effects mediated by CORMs, and to contribute to the development of a therapeutic approach to protect the liver during severe burn injury.

\section{COMMENTS}

\section{Background}

Recent studies have shown various physiologic and immunologic alterations in acute inflammations associated with infection, trauma and thermal injury. Increasing attention has been directed to the role of cytokines in the mechanisms of such alterations. TNF- $\alpha, \mathrm{IL}-1 \beta, \mathrm{IL}-6$, which are pro-inflammatory cytokines, are considered potential mediators of inflammation produced by immunoregulatory cells as well as by a variety of other cell types, and play a major role in the regulation of immune response and inflammation. In our laboratory, it was confirmed that tricarbonyldichlororuthenium ( II ) dimer (CORM-2), one of the novel group of CORMs, inhibited the leukocytes sequestration in liver and downregulated inflammatory response in lung of burn-challenged mice. However, the regulating mechanisms of CORM-2 in the inflammatory response in liver of burnchallenged mice remain unknown. Severe burn injury is a complicated process that involves several host responses, including inflammation, immune response and even SIRS. Different cytokines are likely to be produced during these host responses. Some of these cytokines may be produced in response to the thermal injury. Also, the pathophysiological changes seen in SIRS are often not due to the infectious organism itself but instead to the uncontrolled production of proinflammatory cytokines and chemokines, including TNF- $\alpha, \mathrm{IL}-1 \beta$.

\section{Research frontiers}

Major burn alters immune function, producing an imbalance between pro- and anti-inflammatory cytokine synthesis and increasing susceptibility to post-burn infection and sepsis. Also, severe burn causes damage to multiple organs distant from the original burn wound, leading to multiorgan failure, a serious clinical problem. Liver is one of the most sensitive tissues to ischemia and reperfusion (I/R) injury induced by thermal injury. Different cytokines may be produced in response to the thermal injury. Also, the pathophysiological changes are often not due to the infectious organism itself but instead to the uncontrolled production of proinflammatory cytokines and chemokines, including TNF- $\alpha$, IL-1 $\beta$. Accumulation of these mediators leads to leukocyte recruitment, capillary leak and tissue damage, ultimately producing the lethality of sepsis.

\section{Innovations and breakthroughs}

This is probably the first study which demonstrated CORM-released CO modulates the inflammatory response in the liver of thermally injured mice and the possible associated mechanisms.

\section{Applications}

Our research observed that CORM-released CO modulates liver inflammation and significantly protects liver injury in burn mice by inhibiting the expression of iNOS and NO production, down-regulating expression of pro-inflammatory mediators, including TNF- $\alpha, \mathrm{IL}-1 \beta$.

\section{Terminology}

Carbon monoxide-releasing molecules (CO-RMs): Transitional metal carbonyls have been identified as potential CO-releasing molecules with the potential to facilitate the pharmaceutical use of $\mathrm{CO}$ by delivering it to tissues and organs.

\section{Peer review}

This study seems to be well performed, the methods are adequate. The reason for the study seems sound and solid, the conclusions seem to be relevant and the literature covers the subject.

\section{REFERENCES}

1 Hayashi S, Takamiya R, Yamaguchi T, Matsumoto K, Tojo SJ Tamatani T, Kitajima M, Makino N, Ishimura Y, Suematsu M. Induction of heme oxygenase-1 suppresses venular leukocyte adhesion elicited by oxidative stress: role of bilirubin generated by the enzyme. Circ Res 1999; 85: 663-671

2 Lee TS, Chau LY. Heme oxygenase-1 mediates the antiinflammatory effect of interleukin-10 in mice. Nat Med 2002; 8: 240-246

3 Otterbein LE, Soares MP, Yamashita K, Bach FH. Heme oxygenase-1: unleashing the protective properties of heme. Trends Immunol 2003; 24: 449-455

4 Motterlini R, Mann BE, Johnson TR, Clark JE, Foresti R, Green CJ. Bioactivity and pharmacological actions of carbon monoxidereleasing molecules. Curr Pharm Des 2003; 9: 2525-2539

5 Motterlini R, Clark JE, Foresti R, Sarathchandra P, Mann BE, Green CJ. Carbon monoxide-releasing molecules: characterization of biochemical and vascular activities. Circ Res 2002; 90: E17-E24

6 Motterlini R, Sawle P, Hammad J, Bains S, Alberto R, Foresti R, Green CJ. CORM-A1: a new pharmacologically active carbon monoxide-releasing molecule. FASEB J 2005; 19: 284-286

7 Johnson TR, Mann BE, Clark JE, Foresti R, Green CJ, Motterlini R. Metal carbonyls: a new class of pharmaceuticals? Angew Chem Int Ed Engl 2003; 42: 3722-3729

8 Foresti R, Hammad J, Clark JE, Johnson TR, Mann BE, Friebe A, Green CJ, Motterlini R. Vasoactive properties of CORM-3, a novel water-soluble carbon monoxide-releasing molecule. $\mathrm{Br} \mathrm{J}$ Pharmacol 2004; 142: 453-460 
9 Clark JE, Naughton P, Shurey S, Green CJ, Johnson TR, Mann BE, Foresti R, Motterlini R. Cardioprotective actions by a water-soluble carbon monoxide-releasing molecule. Circ Res 2003; 93: e2-e8

10 Guo Y, Stein AB, Wu WJ, Tan W, Zhu X, Li QH, Dawn B, Motterlini R, Bolli R. Administration of a CO-releasing molecule at the time of reperfusion reduces infarct size in vivo. Am J Physiol Heart Circ Physiol 2004; 286: H1649-H1653

11 Sun BW, Chen ZY, Chen X, Liu C. Attenuation of leukocytes sequestration by carbon monoxide-releasing molecules: liberated carbon monoxide in the liver of thermally injured mice. J Burn Care Res 2007; 28: 173-181

12 Sun B, Sun H, Liu C, Shen J, Chen Z, Chen X. Role of COreleasing molecules liberated $\mathrm{CO}$ in attenuating leukocytes sequestration and inflammatory responses in the lung of thermally injured mice. J Surg Res 2007; 139: 128-135

13 Beutler B, Krochin N, Milsark IW, Luedke C, Cerami A. Control of cachectin (tumor necrosis factor) synthesis: mechanisms of endotoxin resistance. Science 1986; 232: 977-980

14 Netea MG, Kullberg BJ, van der Meer JW. Lipopolysaccharideinduced production of tumour necrosis factor and interleukin-1 is differentially regulated at the receptor level: the role of CD14-dependent and CD14-independent pathways. Immunology 1998; 94: 340-344

15 Otterbein LE, Bach FH, Alam J, Soares M, Tao Lu H, Wysk M, Davis RJ, Flavell RA, Choi AM. Carbon monoxide has antiinflammatory effects involving the mitogen-activated protein kinase pathway. Nat Med 2000; 6: 422-428

16 Faunce DE, Gregory MS, Kovacs EJ. Effects of acute ethanol exposure on cellular immune responses in a murine model of thermal injury. J Leukoc Biol 1997; 62: 733-740

17 Gamelli RL, He LK, Liu H. Macrophage suppression of granulocyte and macrophage growth following burn wound infection. J Trauma 1994; 37: 888-892

18 Stengle J, Meyers R, Pyle J, Dries DJ. Neutrophil recruitment after remote scald injury. J Burn Care Rehabil 1996; 17: 14-18

19 Faunce DE, Llanas JN, Patel PJ, Gregory MS, Duffner LA, Kovacs EJ. Neutrophil chemokine production in the skin following scald injury. Burns 1999; 25: 403-410

20 Lepay DA, Nathan CF, Steinman RM, Murray HW, Cohn ZA. Murine Kupffer cells. Mononuclear phagocytes deficient in the generation of reactive oxygen intermediates. J Exp Med 1985; 161: 1079-1096

21 Hasegawa T, Sakurai K, Kambayashi Y, Saniabadi AR, Nagamoto H, Tsukada K, Takahashi A, Kuwano H, Nakano M. Effects of OPC-6535 on lipopolysaccharide-induced acute liver injury in the rat: involvement of superoxide and tumor necrosis factor-alpha from hepatic macrophages. Surgery 2003; 134: 818-826

22 Mustafa SB, Gandhi CR, Harvey SA, Olson MS. Endothelin stimulates platelet-activating factor synthesis by cultured rat
Kupffer cells. Hepatology 1995; 21: 545-553

23 Kiechle FL, Malinski T. Nitric oxide. Biochemistry, pathophysiology, and detection. Am J Clin Pathol 1993; 100: 567-575

24 Ayala A, Chung CS, Grutkoski PS, Song GY. Mechanisms of immune resolution. Crit Care Med 2003; 31: S558-S571

25 Mannick JA, Rodrick ML, Lederer JA. The immunologic response to injury. J Am Coll Surg 2001; 193: 237-244

26 Moss NM, Gough DB, Jordan AL, Grbic JT, Wood JJ, Rodrick ML, Mannick JA. Temporal correlation of impaired immune response after thermal injury with susceptibility to infection in a murine model. Surgery 1988; 104: 882-887

27 White J, Thomas J, Maass DL, Horton JW. Cardiac effects of burn injury complicated by aspiration pneumonia-induced sepsis. Am J Physiol Heart Circ Physiol 2003; 285: H47-H58

28 Kawakami M, Terai C, Okada Y. Changes of the interleukin-6 levels in skin at different sites after thermal injury. J Trauma 1998; 44: 1056-1063

29 Reddy RC, Chen GH, Tekchandani PK, Standiford TJ. Sepsisinduced immunosuppression: from bad to worse. Immunol Res 2001; 24: 273-287

30 Hayashi S, Takamiya R, Yamaguchi T, Matsumoto K, Tojo SJ, Tamatani T, Kitajima M, Makino N, Ishimura Y, Suematsu M. Induction of heme oxygenase-1 suppresses venular leukocyte adhesion elicited by oxidative stress: role of bilirubin generated by the enzyme. Circ Res 1999; 85: 663-671

31 Nakao A, Moore BA, Murase N, Liu F, Zuckerbraun BS, Bach FH, Choi AM, Nalesnik MA, Otterbein LE, Bauer AJ. Immunomodulatory effects of inhaled carbon monoxide on rat syngeneic small bowel graft motility. Gut 2003; 52: 1278-1285

32 Sawle P, Foresti R, Mann BE, Johnson TR, Green CJ, Motterlini $\mathrm{R}$. Carbon monoxide-releasing molecules (CO-RMs) attenuate the inflammatory response elicited by lipopolysaccharide in RAW264.7 murine macrophages. Br J Pharmacol 2005; 145 800-810

33 Willy C, Dahouk S, Starck C, Kaffenberger W, Gerngross $\mathrm{H}$, Plappert UG. DNA damage in human leukocytes after ischemia/reperfusion injury. Free Radic Biol Med 2000; 28: 1-12

34 Cetinkale O, Senel O, Bulan R. The effect of antioxidant therapy on cell-mediated immunity following burn injury in an animal model. Burns 1999; 25: 113-118

35 Moriyama A, Tabaru A, Unoki H, Abe S, Masumoto A, Otsuki M. Plasma nitrite/nitrate concentrations as a tumor marker for hepatocellular carcinoma. Clin Chim Acta 2000; 296: 181-191

36 Hara H, Mitani N, Adachi T. Inhibitory effect of nitric oxide on the induction of cytochrome P450 3A4 mRNA by 1,25-dihydroxyvitamin D3 in Caco-2 cells. Free Radic Res 2000; 33: $279-285$

37 Rawlingson A. Nitric oxide, inflammation and acute burn injury. Burns 2003; 29: 631-640

S- Editor Liu Y L- Editor Kumar M E- Editor Li HY 